\title{
International Journal of Aviation Science and Technology
}

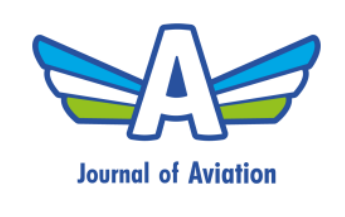

\section{An Assessment of Aircraft Maintenance Technician Competency}

\author{
Tarık Güneş ${ }^{1 \star}$, Uğur Turhan², Birsen Açıkel ${ }^{3}$ \\ ${ }^{1}$ Eskişehir Technical University, Faculty of Aeronautics and Astronautics, tarikgunes@eskisehir.edu.tr \\ ${ }^{2}$ Eskisehir Technical University, Faculty of Aeronautics and Astronautics, uturhan@eskisehir.edu.tr \\ ${ }^{3}$ Kastamonu University, School of Aviation, bacikel@kastamonu.edu.tr
}

\section{Abstract}

Aircraft maintenance activities are one of the most important criteria for the safe and effective execution of aviation operations., In aircraft accidents and incidents, maintenance factor is vital for the development of safety for organizations, authorities, and countries in the aviation field. Effective maintenance activities will also contribute to the costs of organizations by ensuring the safe operations of aircraft with people. Maintenance activities are carried out by maintenance technicians in areas such as hangars or aprons. Aircraft maintenance technicians' performance in performing maintenance activities directly impacts flight safety and technician safety, which in turn has a positive or negative impact on organizations. Improving technician competency assessment processes can reduce maintenance errors, improve technician performance, create positive impacts on safe and efficient flight operations, reduce maintenance costs and benefit of the entire aviation industry. Technician competency should be considered in performance evaluations and assignments by assessing at all levels with the compatibility of widely used human resources management methods. In this study, technician competency assessment processes are mentioned, the effects of these processes on aviation safety are explained and solutions are proposed to develop and apply the assessment processes.
\end{abstract}

Keywords

Aircraft maintenance

Aircraft maintenance technician competency

Competency assessment

Human factors

\section{Time Scale of Article}

Received 2 March 2020

Revised to 29 June 2020

Accepted 9 July 2020

Online date 10 September 2020

\section{Introduction}

Aircraft maintenance activities are one of the direct operational and primary operational activities of air transport, which is the most effective transportation method today, safely, effective and sustainable manner. Performing aviation operations safely and effectively depends on the performance of human resources. Human has an important role in aviation incidents and crashes compared to aircraft and flight-related systems [1].

Pilots, air traffic controllers, and aircraft maintenance technicians are critical human resources in terms of flight safety. These qualified resources are the leading actors in maintaining operations as intended in terms of flight safety and effectiveness. The physical and cognitive processes of these operators may affect their behavior and thus flight efficiency in a good or bad way (Turhan, 2019). In other words, aircraft maintenance technicians are the human resources that create significant added value in the realization of flights as planned.

The competence and performance of aircraft maintenance organizations and maintenance technicians are effective in terms of safety and cost in the environment in which aviation and airline organizations operate. While the performances of the work perform as expected, they provide positive added value in all operations, while the consequences of the negativities may be very destructive.

*: Corresponding Author Tarık Güneş, tarikgunes@eskisehir.edu.tr, Tel: +90 2223213550 ext: 6815

DOI: 10.23890/IJAST.vm01is01.0104 
The purpose of aircraft maintenance activities is to maintain flight operations safely and to ensure the reliability of components and systems at the lowest possible cost. To achieve these goals, it is one of the most important criteria for maintenance technicians to perform the maintenance activities properly [2]. Although it is known that air transportation is one of the safest methods of transportation, an accident or incident that may occur have serious consequences both in terms of its impact and cost.

Although it is known that maintenance activities are vital for aviation safety, the supply of qualified technicians, recruitment and selection practices may be insufficient to supply the ever-increasing demand for qualified human resources in the operational aviation environment. There are problems at the international level regarding aircraft maintenance technician training, and there is a shortage of certified technicians (technicians who approve maintenance tasks) in organizations. Despite knowing the importance of aircraft maintenance, unfortunately, present technology used in the field of maintenance and also the existing structure of the aircraft maintenance documentation, which is the main ground of maintenance operations, remains insufficient [3].

The current structure of the maintenance documents used during maintenance tasks does not provide sufficient benefits for the efficient maintenance of technician competence assessment procedures. Preparing and using maintenance documents with interactive technologies will provide a significant improvement in the more objective and effective maintenance of technician competency assessment processes.

The competence of aircraft maintenance technicians can be defined as all of the knowledge, skills, behaviors, and attitudes used to perform their tasks within the scope of aircraft maintenance and repair activities. Task performances depend on the level of these basic knowledge, skills, and behaviors. The level of knowledge and experience of maintenance technicians is an important factor that closely affects the cost of direct maintenance for organizations. If there is a lack of technician training, it will lead to the unnecessary dismantling of available components and ordering spare parts and will reduce efficiency in troubleshooting. Because more time is needed to complete maintenance activities, more manpower will be needed for the planned maintenance tasks.

This will also cause problems in the use of test equipment and the use of technical documentation, and all these adversities will increase the maintenance cost (Mercan, 1999). Despite this information, it is generally assumed that technicians are not involved in the airworthiness process. The technician is the last link in the airworthiness chain. The owner of the last signature of the aircraft before the flight [4]. Therefore, important roles such as assessment of technician competence and flight availability approval should be assigned to qualified and competent aircraft maintenance technicians.

In this study, it is aimed to examine the factors that affect their competence and thus their performance and to contribute to the field literature and operational processes for competency assessment.

Factors affecting the performance of technicians can be listed as cognitive factors, physical factors, organizational factors, and procedural factors. Accurately measuring, analyzing and evaluating these factors will help improve technician performance, have positive impacts on safe and efficient flight operations, reduce maintenance costs and benefit the entire aviation industry.

\section{Aircraft Maintenance and Maintenance}

\section{Technicians}

Aircraft maintenance activities are required to perform safe flights that meet the requirements for airworthiness. An aircraft is delivered from the manufacturer to the operator under conditions in which the systems are fully operational and airworthiness requirements are met [5]. Maintenance activities are carried out to maintain and improve the performance and robustness of the aircraft. Maintenance activities include visual inspection, repair, repair, replacement and replacement of parts [5]. The maintenance activities are carried out by authorized technicians by the standards, methods, techniques, and instructions specified in the regulations, in the use of appropriate tools and materials and appropriate facilities or areas under all environmental conditions.

The main purpose of aircraft maintenance; to keep the aircraft within the design limits in terms of performance and reliability [7]. Aircraft maintenance is an important process where safety, security and quality requirements are strictly applied. Maintenance procedures are determined by the manufacturer and controlled by the competent authorities throughout the operation. Aircraft maintenance is therefore carried out by regulations such as EASA-145 (European Aviation Safety Agency) and MSG-3 (Maintenance Guidance Guide) [8]. Aircraft operators are obliged to keep the airplane they operate in an airworthy condition, to establish the necessary organization to perform maintenance activities or to purchase them. In general, maintenance services require appropriate maintenance workshops or hangars, appropriate and sufficient equipment, tools, equipment, infrastructure systems, maintenance technicians and certified technicians [9]. The responsibility of aircraft maintenance, which is the most basic part of the airworthiness, lies with all employees of the organization, especially the aircraft operators.

Maintenance activities are the key factors in achieving the goals that the airline organizations plan at the foundation stage and succeeding in this direction, 
increasing the reliability of the aircraft, using the aircraft efficiently, performing the operations within the safety framework, and increasing the respectability of the organization and aviation sector [10].

Human factors play an effective role in aviation accidents or fractures that have occurred. Human factors can also be cited as the cause of maintenance errors. Individual-based errors can be caused by education deficiencies, planning deficiencies, human factors such as attention, perception, stress, workload and situational awareness. Although organizations take several measures to prevent these situations, which cause serious cost and dignity loss for them, the increasing number of flights and airplanes in the sector, the spread of automation systems and the increase in competition make the maintenance technicians capable of making mistakes from time to time.

As shown in previous studies, the maintenance factor is very effective in all aviation accidents. $28.6 \%$ of the fatal aviation accidents between 1999 and 2008 were responsible for the maintenance factor (Froslee, 2011). Although technological advances in the aviation sector have positively affected air traffic safety and caused a decrease in aviation accidents, there has not been a satisfactory decrease in the rate of maintenance-related accidents and incidents. Although the rate of maintenance errors in aviation accidents gives different results in the researches, it can be said that this rate is approximately $12-20 \%$ [11].

In the aviation area, approximately 12 man-hours of maintenance are performed per flight hour. Considering these periods, it is not surprising that $12-15 \%$ of aviation accidents occurred due to maintenance. (Rashid et al, 2014). The studies emphasize that proactive methods should be developed to reduce these rates and their necessity is vital for the safety of aviation operations. [12].

Although maintenance errors can be prevented without causing accidents, situations such as flight cancellation and delays create serious costs for organizations. According to the researches, $20-30 \%$ of the engine stopping events occurred during the flight as a result of maintenance errors, while approximately $50 \%$ of the engine-induced flight cancellations or delays are due to maintenance errors. Even the lowest level of maintenance failure can somehow threaten operational safety.

An efficient maintenance system is an important factor in the airline's goal of achieving its cost objectives. Reducing flight cancellations, delays and air returns will be beneficial for the operator with the efficient maintenance required [13].

The main purpose of all airlines is to transport their passengers and / or cargo from one point to another for profit. Maintenance activities enable aircraft to perform operations within the framework of the planned flight schedule. Maintenance activities are carried out through maintenance programs determined for these purposes.

The appropriately planned and established aircraft maintenance organization will be successful in the safety, component and aircraft reliability and cost issues that are the main objectives of aircraft maintenance and will contribute to the achievement of the objectives of the organization.

For this reason, the objectives of maintenance activities should be considered and planned during the establishment phase of the organizations [14]. The objectives of maintenance activities can be grouped under three main headings. These; safety, availability and, cost.

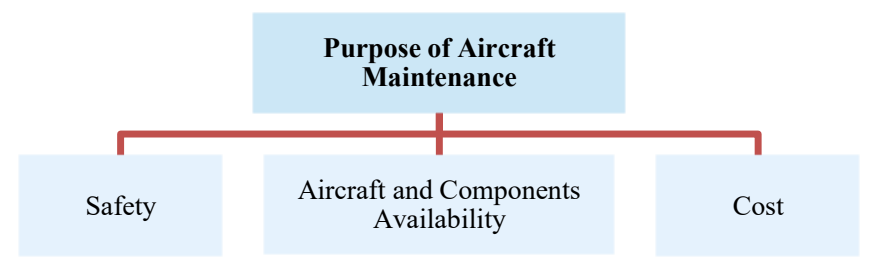

Fig. 1. Purpose of aircraft maintenance

It is aimed to perform maintenance activities at the highest level of safety, optimum aircraft and component reliability at the lowest possible costs. However, these objectives may not always be possible in the aviation industry, where flights and maintenance activities are carried out at all times of the day, in all weather conditions.

Maintenance activities are the key factors in increasing aircraft reliability, efficient use of aircraft, carrying out operations within the framework of safety, and increasing the reputation of the organization and the sector [9]. The objectives of aircraft maintenance are directly related to each other and all three objectives need to be considered and realized together. When the required levels of safety are reached, maintenance errors will be reduced, maintenance-related accidents, incidents, delays, and cancellations will be reduced and thus, significant contributions will be made to organizations in terms of cost. On the other hand, organizations' efforts to reduce costs in an unplanned manner may have negative impacts on safety.

Failure to keep sufficient material in stocks, reducing the number of employees, avoiding the necessary investments in maintenance areas may also increase maintenance errors. This may directly affect the reliability of aircraft and components.

Proper maintenance activities in aprons, hangars, and 
workshops have an important place in aviation safety. In addition to accidents and incidents caused by maintenance failure, maintenance activities may also indirectly affect other causes of the accident, such as pilotage and material factors.

\subsection{Aircraft Maintenance Technician}

The main factor in the successful maintenance of aircraft maintenance and repair activities is "human". For the organization to operate profitably, it is necessary to employ technicians who can provide timely and safe service.

The technician following the requirements of the aircraft maintenance job descriptions must be recruited and trained. Information on job descriptions and requirements can be collected through business analyzes within the organization itself, as well as the work of international organizations [15].

The aircraft maintenance system is a complex structure with human and machine components as one of the critical elements ensuring the reliability and safety of the transportation system. The aircraft maintenance technician who performs aircraft maintenance for operational efficiency and safe flight is one of the cornerstones of this system.

An aircraft maintenance technician is a person who performs scheduled or unplanned maintenance for aircraft units [16]. Technicians can think analytically as required by the profession, have a strong perception and are well educated. They continue their education in technical education, business, and management after vocational education.

Maintenance technician concept; aircraft technician, assistant technician, and service worker class. The technician's job descriptions may be inspection, repair, revision, maintenance or aircraft ground handling activities. The concept of maintenance personnel also includes support personnel (administrative staff, programmers, planners, supervisors, and managers) responsible for decision-making, analysis or recordkeeping during planning or maintenance execution due to their tasks [17].

Aircraft maintenance technicians can be mainly divided into mechanical maintenance technicians and avionics maintenance technicians. It is also possible to subdivide them into subheadings. Aircraft mechanical maintenance technicians are technicians who perform operations such as inspection, repair, and service of aircraft structure and power units. Aircraft maintenance technicians have an important position in the aviation field. Generally, they perform maintenance activities in a hangar environment or in areas such as apron which can be considered as noisy and dangerous. Their work is very tiring and requires enough physical activity to adversely affect their performance [18].

The duties and responsibilities of the technicians include the safety of the passengers and crew and the airworthiness of the aircraft. The responsibility of the maintenance technician also continues in the service, maintenance and inspection operations of the aircraft [19]. At every stage of maintenance, technicians must interact with the equipment, the work area, the maintenance books, and the information in electronic or hard copy sources required by maintenance activities.

Since its inception, the International Civil Aviation Organization (ICAO) has been involved in operational procedures and competencies of the aircraft technician. The aircraft maintenance technician is licensed by a civil aviation authority approved by ICAO to ensure appropriate safety standards. In this process, ICAO specifies countries' licensing standards with international validity, sets out the differences between these standards, uses a common text and terminology, provides a common platform for the recognition of licenses, and allows countries to audit regulatory systems.

According to ICAO, licensing is a means or method that authorizes the technician to perform specific activities by the authority. Licensing of aircraft maintenance technicians under the Chicago Convention is a responsibility for each country. In the European Union countries, maintenance technicians are licensed under EASA Part 66. In this way, a common license definition was created for all EASA affiliated technicians. According to EASA Part 66, maintenance technician license categories are divided into three categories: A, B, and C. These categories are known as authorized technician classifications in the aircraft maintenance system [20]. To use the competencies that these categories have recognized, there are certain requirements that the technician should provide.

For the licensing of technicians, they must meet the requirements of the civil aviation authority to which they belong. Successful completion of written, oral and test exams is required for the licenses to be applicable. This license is not required to work as an assistant technician in the aircraft maintenance task, but the license required to be able to service the aircraft, ie to become a certifying technician, must be obtained (SHGM, 2013). Licensed technicians often charge more and are preferred by employers.

Maintenance activities carried out on an aircraft are regularly checked by national and international authorities. Aircraft maintenance technicians can be classified according to their certification. A valid aircraft maintenance technician license following the provisions of these instructions is required to perform repair, maintenance, revision, inspection, and service operations to ensure the airworthiness of aircraft or components [21].

\subsection{Become an Aircraft Maintenance Technician}

Currently, there is no licensing requirement to work as a 
technician or mechanic in aircraft maintenance activities, while licensed or confirmatory maintenance techniques.

The aircraft maintenance technician must first fulfill the requirements and obtain a license according to a license category he/she has chosen to become a certifying technician. License categories are divided into three categories: A, B, and C. The maintenance technician must provide some basic knowledge, experience, and foreign language requirements to be licensed in the relevant categories.

After passing the relevant module exams for A license, one year is required if the technician has completed Part 147 training, two years for a qualified technician, and three years if he/she has not received basic technical training. After passing the relevant module exams for B license, the technician is required to have two years of experience in Part 147, three years for a qualified technician, and five years if he/she has not received basic technical training. Three or five years of experience are required depending on the authorization to use the $\mathrm{C}$ license. The validity period of the licenses is five years and renewal is required at the end of this period (Fig.2, 3.) [21].

The certifying technician refers to the technician responsible for the maintenance output of the component or aircraft to certify that the maintenance activity has been completed following the requirements of the relevant authority [21]. To become a certified technician, it is necessary to have the appropriate aircraft maintenance license and to have the type training certificate according to the duty of the aircraft concerned [6].

To become an approved technician, the organization in which the technician works must also be authorized. This authority is renewed once every two years and the technician is required to spend at least six months of two years working in aircraft maintenance. The age limit for becoming a licensed technician is 18 , while this is 21 for the certifying technician. This means that even if the licensee fulfills all the requirements, he/she cannot become an approved technician before she/he is 21 years of age.

Technological advances in the aviation industry have also affected aircraft maintenance technicians and have made it imperative that they become compatible with complex aircraft systems with advancing technology. For maintenance technicians to achieve this compliance, it has become inevitable that technician training should be adapted to today's conditions in organizations and schools providing maintenance training [22]. Welltrained and qualified aircraft technicians with expertise in specialized equipment have a significant impact on preventing maintenance-induced delays. The shortage of qualified technicians is becoming an increasingly large problem for the industry.

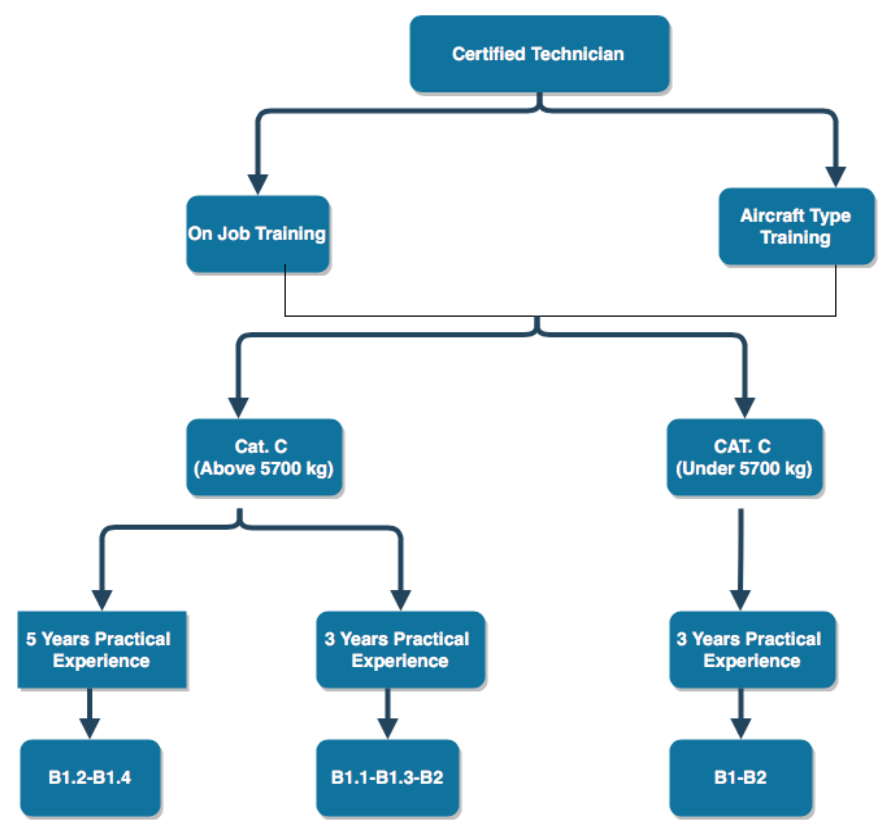

Fig. 2. Become an aircraft maintenance technician (a)

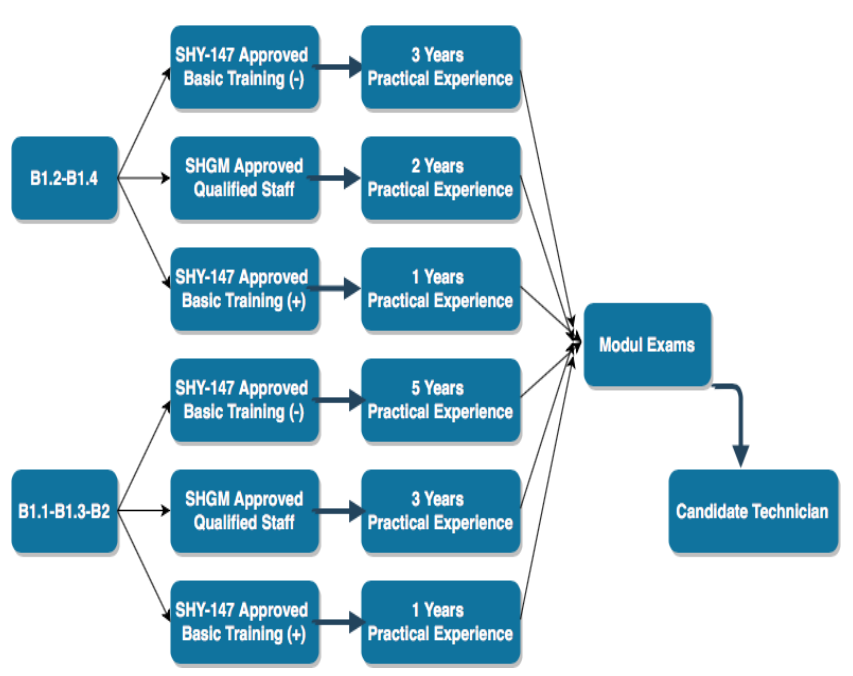

Fig. 3. Become an aircraft maintenance technician (b)

The aviation industry needs well-trained, qualified and professionally qualified maintenance technicians. Graduates of schools providing care education cannot adequately meet this demand. The training received from graduates of educational institutions could not keep up with the changing technology in the aircraft maintenance environment [23]. Students do not have sufficient job training experience and as a result, are not sufficiently prepared to move to work. After receiving the basic training required for the profession, the aircraft technician should keep himself up to date, develop his skills, acquire new processes and be able to master the procedures.

To summarize the training, licensing and promotion processes of the aircraft maintenance technician; the candidate technician must first receive basic and practical training from a maintenance training organization approved by the relevant authorities. 
Afterward, they have to pass the module exams required for licensing determined by international authorities and as a result, they must be authorized by the organization they work for. The licensed technician can be sent to type training if required by her/his organization and work as an approving technician in any type of aircraft. These include theoretical and on-the-job training (OJT). A technician working as an approving technician may also work in the aircraft maintenance field by taking update training, human factors training and organization procedures training, if deemed appropriate by his organization.

\section{Evaluation of Aircraft Maintenance}

\section{Technician's Competency}

The concept of competence for aircraft maintenance can be defined as all of the knowledge, skills, and behaviors that technicians use to perform their duties in aircraft maintenance and repair. Assessing the competencies of maintenance technicians can be described as defining, measuring, and using competency assessment results of technicians performing aircraft maintenance and repair activities. Competence assessment activities should be implemented throughout the process of selecting and placing the maintenance technician, assisting technician and becoming a certified technician.

Determination of recruitment criteria, selection of recruitment and assignment to work units, determination of transition criteria between career levels and application of competency assessment criteria in the determination of transition criteria to the certified technician will provide important benefits in aviation safety. They will also be able to use task-specific training, identify performance problems and prevent frustration.

\subsection{Aircraft Maintenance Technician Competency \\ Levels}

Candidates wishing to become an aircraft maintenance technician may apply for the job if the institutions providing maintenance services meet the criteria stated in the job advertisements. As the first stage of competence assessment, the selection and placement stage is accepted. At this stage, organizations determine occupational, physical and cognitive competencies for the care technician profession and thus create a recruitment announcement and the first qualifications are performed at this stage. Candidates who pass the pre-evaluation stage are invited to the selection exams under the conditions determined by the organizations. In the selection exams, candidates can be asked verbal and written questions about the field. The candidates who are successful in the selection process can work as assistant technicians. In line with the criteria and needs determined by the organizations, assistant technicians are assigned to the units where they will work. The technicians who pass the required module exams and complete the experience period can be appointed as a certified technician if the organization deems appropriate.

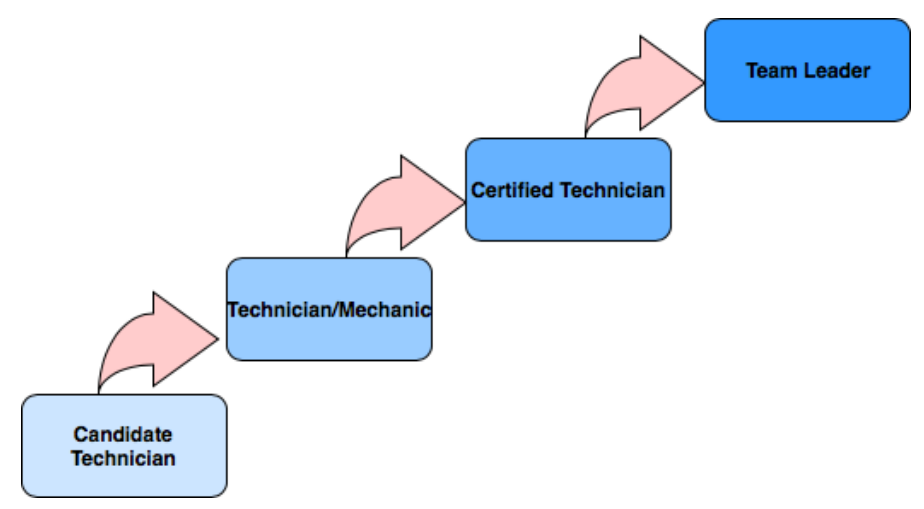

Fig. 4. Aircraft maintenance technician competency levels

The effectiveness of the criteria and methods identified and applied in all of these stages will directly affect the efficiency and efficiency of the aircraft maintenance technician and will be a decisive criterion for aviation safety.

The selection of a candidate who is not suitable for the profession or does not have sufficient competence during the recruitment and selection phase may adversely affect the efficiency of all subsequent stages.

\subsection{Evaluation of Aircraft Maintenance}

\section{Technician's Competency}

Effective evaluation of the competence of maintenance technicians is crucial. In this way, it will be possible to carry out value-added studies in terms of efficiency of technicians, job satisfaction and career development. In general, maintenance technicians' methods of performing their tasks are standard, which may facilitate convenience evaluation.

The task cards used by the maintenance technicians during the maintenance activities are the work orders prepared by the maintenance organizations according to the rules of the international authorities.

On these task cards, maintenance technicians write maintenance tasks assigned to them, for example, the technician makes part changes and completes the job as well as the status of the maintenance planning units by writing them to the maintenance planning units. The task cards also include man-hour information related to the defined job.

These cards, which are stored in the archives by the maintenance planning units, contain information about who or by whom the task was performed, whether the task was completed, whether or not changes were made. Based on this information, it is possible to implement an evaluation mechanism for maintenance technicians 
effectively.

In this context, organizational issues such as whether the work is performed, how unplanned failures occur, increases in maintenance costs are considered as performance indicators and individual factors may remain in the background.

It can also provide benefits in maintenance organizations such as maintaining appropriate data about technicians and providing a return system, effectively planning the tasks assigned to them, and the functioning of reward, punishment, and promotion systems.

In such cases, the efficiency of maintenance technicians may have positive effects on the operation of the planning system, flight operations that need to be carried out safely and effectively, and reduction of maintenance costs.

The competency assessment methods that can be applied to maintenance technicians can be listed as follows.

Direct Observation: Maintenance technicians may be observed during their duties by chief technicians, team chiefs or other technicians who are more senior. During this observation process, it will be possible to have information about whether the technician performs the maintenance task effectively, the effectiveness of the use of documents and tools, whether he/she uses personal protective equipment and safety perception.

Tracking Records: In this method, records such as maintenance documents used by technicians, training received, and evaluation results will be examined and data will be provided on the competence of the technician.

Review and Analysis of Quality Control Records: The quality assessment records maintained by the quality units of the maintenance organizations will be periodically reviewed to provide an assessment of the competencies of maintenance technicians.

Safety Management System (SMS) Records Review and Analysis: By examining the records kept by the Safety Management System units of maintenance organizations, technicians will be able to learn about the errors, safety perceptions, and causes of errors during the maintenance tasks.

Comparison of Technician Performance: While evaluating the results to be obtained by direct observation, monitoring of records, and examination of quality and safety management system records, the performances of employees can be compared. This will provide information on the competence and efficiency of performance evaluation criteria.

The methods given above can be used as competence assessment methods in aircraft maintenance companies, and the implementation of these practices will directly contribute to aviation safety and maintenance activities and thus have a positive impact on cost.

After an appropriate competency assessment process to be carried out during the selection process, it is necessary to make systematic observations and maintenance records of technicians working in maintenance environments within certain programs.

These data will be able to conclude how effectively the maintenance technician performs the maintenance tasks and whether they comply with the safety directives.

The extent to which the technician correctly performs the use of documents and materials during his or her duty, whether he uses personal protective equipment or not, will provide data on both professional competence topics and human factors and safety issues.

In addition to these, quality control records and SMS records can be examined and potential errors that the technician has made or will be able to make can be identified and the aspects that need to be improved in terms of human factors and professional competence will be identified.

In this way, a more effective maintenance environment can be provided, and maintenance errors can be reduced.

In all of these evaluations, a feedback system for technicians should be established and the technicians should be informed about the evaluations and solution suggestions with the applications such as the case study method.

\section{Conclusion}

One of the most important steps in safe and effective flight operations is aircraft maintenance activities. Considering the difficult working conditions of maintenance technicians who will perform maintenance activities, it is necessary to analyze the technician competency assessment processes and apply the necessary arrangements from the selection and placement process to the approval technician process. Apart from the assessment of competencies such as professional knowledge, foreign language knowledge, document usage knowledge, the application of human factors evaluations such as the ability to work under time pressure, adaptation to shift work system, situational awareness, attention and perception measurement is very important in terms of aviation safety.

In the basic training of aircraft maintenance technicians and the future work environments, the authorities and all relevant stakeholders should act with the support of culture to develop competency assessment.

In the recruitment process of technicians, professional competencies should be evaluated as applied and professional competencies should be applied in terms of appointment to operational units and promotion to approving technicians. 
Likewise, language proficiency should be applied as a measure and assessment of reading, listening, writing, and speaking skills both in recruitment and subsequent processes.

In addition to these assessments, it is necessary to evaluate the compliance of the candidate technicians to the profession, especially during the selection process.

During the selection process, the subjects such as attention, perception measurement, working under time pressure and stress, and safety culture measurement should also be evaluated.

Unless appropriate criteria are applied and evaluated during the selection process, adversities may be experienced in all of the technician's next career development stages.

Maintenance faults, which directly or indirectly have an important place in aircraft accidents, crashes, and incidents, will be significantly reduced if these assessments are made appropriately. In this way, flight operations will be performed in a safer manner, costs resulting from maintenance errors will be reduced and a safer maintenance site will be created. Together with all these features and in this way it will make positive contributions to the whole aviation sector.

\section{References}

[1] Turhan, U. (2019). Operator Performance in Aviation Safety: Human Factors and Neuroscience. New Trens in Management Studies, edited by Özer Yllmaz, Peter Lang, 263-276. Berlin.

[2] Shanmugam, A. \& Paul Robert, T, (2015). Ranking of Aircraft Maintenance Organization Based on Human Factor Performance Computers \& Industrial Engineering, no. 88, 410-416.

[3] Güneş, T. (2016) Hava Aracı Bakım Dokümanlarının Emniyet ve Etkinliğinin Artırılmasına Yönelik Bir Yaklaşım Yüksek Lisans Tezi, Anadolu Üniversitesi.

[4] Doll, R.E. (2001) Repair station report: the year 2000. Air Carrier MRO Handbook, edited by J. Hessburg, 27-31. New York: McGraw-Hill Companies.

[5] Garris, J.T. (2003). Aircraft Maintenance. The Standart Handbook for Aeronautical and Astronautical Engineers, edited by M. Davies, 18.118.82. New York: McGraw Hill.

[6] Hessburg, J. (2001) Maintenance Fundamentals. Air Carrier MRO Handbook, edited by Jack Hessburg, 245-270. New York: McGraw-Hill Companies.

[7] Friend, C. H. (1997). Aircraft Maintenance Management. London: Harlow, Longman.

[8] Yu, J, \& Gulliver, S. (2011) Improving Aircraft Maintenance, Repair, and Overhaul: A novel Text Mining Approach. International Conference on Intelligent Computing and Intelligent Systems' Nov
18-20. Guangzhou, China.

[9] Torum, O. (1993). Sivil Havacılık Hizmetinde Uçak Bakımı. IV. Ulusal Havacılık Sempozyumu, Eskişehir: Anadolu Üniversitesi, 103-118.

[10] Yuksel, S. (2008). Türkiye'deki Hava aracı Bakım Faaliyetlerinde Dis, Kaynak Kullanımının Araștırılması ve Degerlendirilmesi. Yuksek Lisans Tezi. Anadolu Universitesi.

[11] Froslee, H.M. (2011). Factors Leading to Human Error in Commercial Aviation Line Maintenance., Ph.D. Thesis., Walden University.

[12] Rashid, H. Place, S, \& Braithwaite, G.R. (2014). Eradicating Root Causes of Aviation Maintenance Errors: Introducing the AMMP Cognition, Technology and Work, no. 16, 71-90.

[13] Van den Bergh, J, De Bruecker, P, Beliën, J, \& Peeters, J. (2013) Aircraft Maintenance Operations: State of the Art. HUB Research Paper., Portugal: Lisbon.

[14] Paluszek, G. (2014). Planning Efficient Airplane Maintenance Facilities. Boeing Aero., no. 54, 19-24.

[15] Mercan, E. (1999). Havayolu ve Havacılık İşletmelerinde Uçak Bakım Organizasyonu, Yuksek Lisans Tezi., Anadolu Universitesi.

[16] Kinnison, H. (2007). Aviation Maintenance Management McGraw-Hill Companies.

[17] Wade, E.G. (2011) Exploring the Effect of Human Factors Regulations on Aviation Maintenance Organizations. Ph.D. Thesis., Northcentral University.

[18] Pourcho, J.B. (2008). Augmented Reality Application Utility for Aviation Maintenance Work Instruction. Master Thesis. South Carolina: Purdue University.

[19] Haines, R.L.Jr. (2008). The Relationship Between Learning Styles and Test Performance in Aviation Maintenance Technicians. Ph.D. Thesis, Capella University.

[20] EASA, (2012). Certifying Staff-Part 66, Luxembourg: Publications Office of the European Union.

[21] SHGM. (2013). Onaylı Hava Aracı Bakım Kuruluşları Talimatında (SHT-145). Ankara: Sivil Havacılık Genel Müdürlüğü.

[22] Chaparro, A, Rogers, B, Hamblin, C, \& Chaparro, B. (2004). Final Report: A Comparison of Three Evaluative Techniques for Validating Maintenance Documentation. Embry Riddle Aeronautical University Scholarly Common Publications.

[23] Sadasivan, S. (2008). Effective VR: Interplay of Presence, Perception, Fidelity and Transfer Effects in the Development of Inspection Training Simulators. Ph.D. Thesis, South Carolina. 